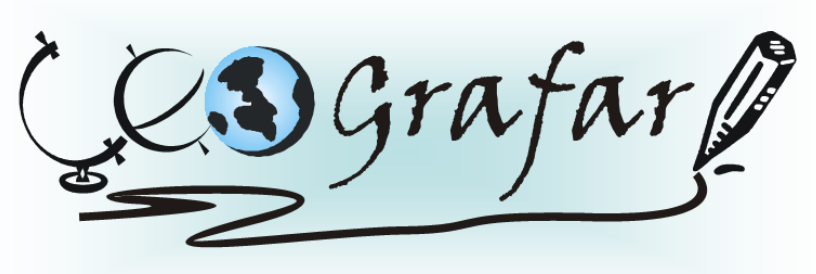

Revista Eletrônica do Programa de Pós-Graduação em Geografia - UFPR

\title{
ANÁLISE DA QUALIDADE DA PAISAGEM DA ORLA MARINHA DE PONTAL DO PARANÁ, PR, BRASIL
}

ANALYSIS OF LANDSCAPE QUALITY OF PONTAL DO PARANÁ SHORE, PR, BRAZIL

\section{(Recebido em 22.04.2013; Aceito em: 09.09.2013)}

\author{
Angeline Martini \\ Doutoranda em Engenharia Florestal \\ Universidade Federal do Paraná \\ Curitiba, PR, Brasil \\ e-mail: martini.angeline@gmail.com \\ Nájila Souza da Rocha \\ Mestranda em Engenharia Florestal \\ Universidade Federal de Santa Maria \\ Santa Maria, RS, Brasil \\ e-mail: najila.rocha2011@gmail.com \\ Luciene Ribeiro \\ Prof ${ }^{a}$. Dra . do curso de Engenharia Ambiental \\ Pontifícia Universidade Católica do Paraná \\ Curitiba, PR, Brasil \\ e-mail: lucienefloresta@gmail.com \\ Daniela Biondi \\ Profa ${ }^{\text {. Dra }}$. do Dep. de Ciências Florestais \\ Universidade Federal do Paraná \\ Curitiba, PR, Brasil \\ e-mail:dbiondi@ufpr.br
}

\begin{abstract}
RESUMO
O estudo da qualidade da paisagem é uma ferramenta de grande importância para promover um planejamento adequado das regiões, pois permite compreender 0 processo de funcionamento e dinâmica da paisagem, o que evita a deterioração dos recursos naturais. $O$ presente estudo teve como objetivo realizar uma análise da qualidade da paisagem da orla marinha do município de Pontal do Paraná, PR. Para
\end{abstract}


isto foram aplicados os dois métodos de estudo da paisagem, direto e indireto. Com o método direto realizou-se uma valoração visual in loco e com o indireto, uma análise dos componentes por meio de fotografias para averiguar a participação de cada elemento no valor total da qualidade da paisagem. Os resultados indicaram que a união dos dois métodos foi uma ferramenta muito útil e adequada, possibilitando uma classificação da paisagem mais criteriosa do que as obtidas apenas por um método. Concluiu-se que os atrativos naturais e o grau de limpeza da praia foram os fatores responsáveis pela elevação da qualidade da paisagem. Por outro lado a interferência antrópica e a supressão da vegetação foram os elementos responsáveis pela redução da qualidade.

Palavras-chave: Análise da paisagem, Orla marinha, Litoral.

\section{ABSTRACT}

The landscape studies generated by analysis enables a specific design which contributes to the understanding of the process operation, dynamics avoids the deterioration of natural resources. This study aims to perform an analysis of the quality of the landscape of the city of marine shore Pontal do Paraná, Paraná. Thereunto the direct and indirect method of landscape studies were applied. With the direct method a visual assessment was held and with the indirect method a component analysis, through picture, to ascertain the contribution of each element in the total landscape quality. The results indicated that the union of methods proved to be a useful and appropriate, enabling a landscape classification more discerning than those obtained by one method alone. It was concluded that the natural attractions and the degree of cleanliness of the beach were the factors responsible for raising the quality of the landscape. To the antagonistic, human interference and the removal of vegetation elements were responsible for the decrease in quality.

Keywords: Analysis of landscape, Marine shore, Coast.

\section{INTRODUÇÃO}

Ambientes costeiros são os locais mais almejados para moradia e lazer pela sua beleza e encanto. No Brasil, muitas capitais e outras cidades de menor porte se encontram ao longo das regiões litorâneas ou muito próximas dela. Ignácio et al. (2004) enfatizou que a zona costeira abriga cerca de $70 \%$ da população mundial e esse grande contingente populacional gera uma pressão que intensifica a perda de propriedade dos processos naturais e que o potencial econômico de regiões costeiras depende, dentre outros fatores, da sua estabilidade morfológica.

O Plano Nacional de Gerenciamento Costeiro - PNGC (BRASIL, 2012), criado em 1988 foi insuficiente para impedir que ações antrópicas pudessem comprometer 
a qualidade ambiental desse ecossistema. No entanto, 16 anos depois, foi editado 0 Decreto Federal n 5.300, de dezembro de 2004, que estabeleceu os limites a serem respeitados no ecossistema costeiro, situação que colocaria na ilegalidade grande parte da área urbanizada da orla marítima brasileira, se tal decreto fosse respeitado.

Falcão et al. (2005) afirmam que apesar do valor ambiental e paisagístico do ecossistema costeiro brasileiro, estes são relegados a um segundo plano, constituindo apenas cenários para as atividades sociais e de lazer que se desenrolam na praia. O Brasil apresenta um vasto litoral, com cerca de 8.000 quilômetros de extensão e na região sul, a linha da costa possui $1.310 \mathrm{~km}$ de comprimento, sendo o litoral do Estado do Paraná um dos menores, representando apenas $100 \mathrm{~km}$ deste total (GEOBRASIL, 2002).

De acordo com o Projeto Orla, desenvolvido pelo Ministério do Meio Ambiente (BRASIL, 2010) e outros órgãos, o município de Pontal do Paraná tem na sua extensão de orla a área mais valorizada e frágil de seu território. Segundo este relatório, há uma percepção errônea da população sobre a praia e a restinga. A restinga é compreendida como uma vegetação que retarda o desenvolvimento do turismo e a urbanização. Por causa dessa percepção, muitos trechos da orla do município já foram alterados e urbanizados sem critério, arborizados com espécies exóticas, ocupados irregularmente e degradados. Ainda, segundo este relatório, outras extensões do território estavam preservadas e pouco alteradas, criando um panorama geral que ainda permitia a implementação de ações de conservação.

Manosso (2005) salientou que os estudos integrados de paisagem contemplam arranjos que se inserem nas dinâmicas socioeconômicas sobre um plano de atributos e elementos físicos, dotados de funcionalidade própria no espaço e no tempo. Desta forma, é possível conhecer as fragilidades e potencialidades das diversas paisagens. Nucci (2010) ressaltou que conhecer os arranjos de interação da paisagem com outros elementos a ela associados permite seu planejamento de forma adequada e que o planejamento da paisagem se constitui, atualmente, em um importante instrumento para a organização do espaço utilizado, tal como a proteção e manejo da natureza e da paisagem em áreas urbanizadas ou não.

O estudo da paisagem, gerado por análises especificas, propicia condições favoráveis ao conhecimento do bom uso da terra, pois segundo Laurie (1975), tal planejamento possibilita à compreensão do processo de funcionamento dela, bem 
como, evita a deterioração dos recursos naturais presentes em determinado espaço paisagístico.

Existem inúmeras ferramentas que auxiliam no estudo da paisagem, o geoprocessamento é uma das alternativas mais baratas e práticas, pois além de entrelaçar dados que tem como meta auxiliar no zoneamento, planejamento e gestão racional dos espaços territoriais, destina-se, como explica Xavier-da-Silva (2011) a tratar os problemas ambientais levando em conta a localização, a extensão e as relações espaciais dos fenômenos analisados.

Conforme relato do Ministério do Meio Ambiente (BRASIL, 2010), no estudo denominado "Panorama da conservação dos ecossistemas costeiros e marinhos no Brasil", nos últimos anos, a percepção do mundo sobre o nível de degradação dos ecossistemas costeiros e marinhos aumentou substancialmente, fato que estimulou a realização de estudos e propostas de ação para conter e reverter as causas que conduzem ao comprometimento ambiental dessas regiões.

Neste sentido, estudos que contribuam com o conhecimento do nível de qualidade da paisagem da orla marinha paranaense representa uma contribuição positiva na valorização do ecossistema costeiro brasileiro e possibilita a geração de informações que subsidiam a melhor gestão de um ambiente de alta relevância turística e econômica para o município de Pontal do Paraná. Desta forma, o objetivo deste trabalho foi determinar a qualidade da paisagem da orla marinha de Pontal do Paraná - PR, Brasil.

\section{MATERIAL E MÉTODO}

A área de estudo escolhida foi a orla do município de Pontal do Paraná (Figura 1). Emancipado em 1995, o município ocupa uma área de $199,873 \mathrm{Km}^{2} \mathrm{com}$ 20.920 habitantes (INSTITUTO BRASILEIRO DE GEOGRAFIA E ESTATÍSTICA IBGE, 2012). Situa-se na planície costeira de Praia de Leste, distando cerca de 94 km de Curitiba, capital do Estado do Paraná. Segundo Simião e Fischer (2004) e Conselho de Desenvolvimento Territorial do Litoral Paranaense - COLIT (2004), o município possui altitude de 3 metros em relação ao nível do mar e encontra-se entre as coordenadas $25^{\circ} 67^{\prime} 36^{\prime \prime} \mathrm{S}$ e $48^{\circ} 51^{\prime} 11^{\prime \prime} \mathrm{W}$. 


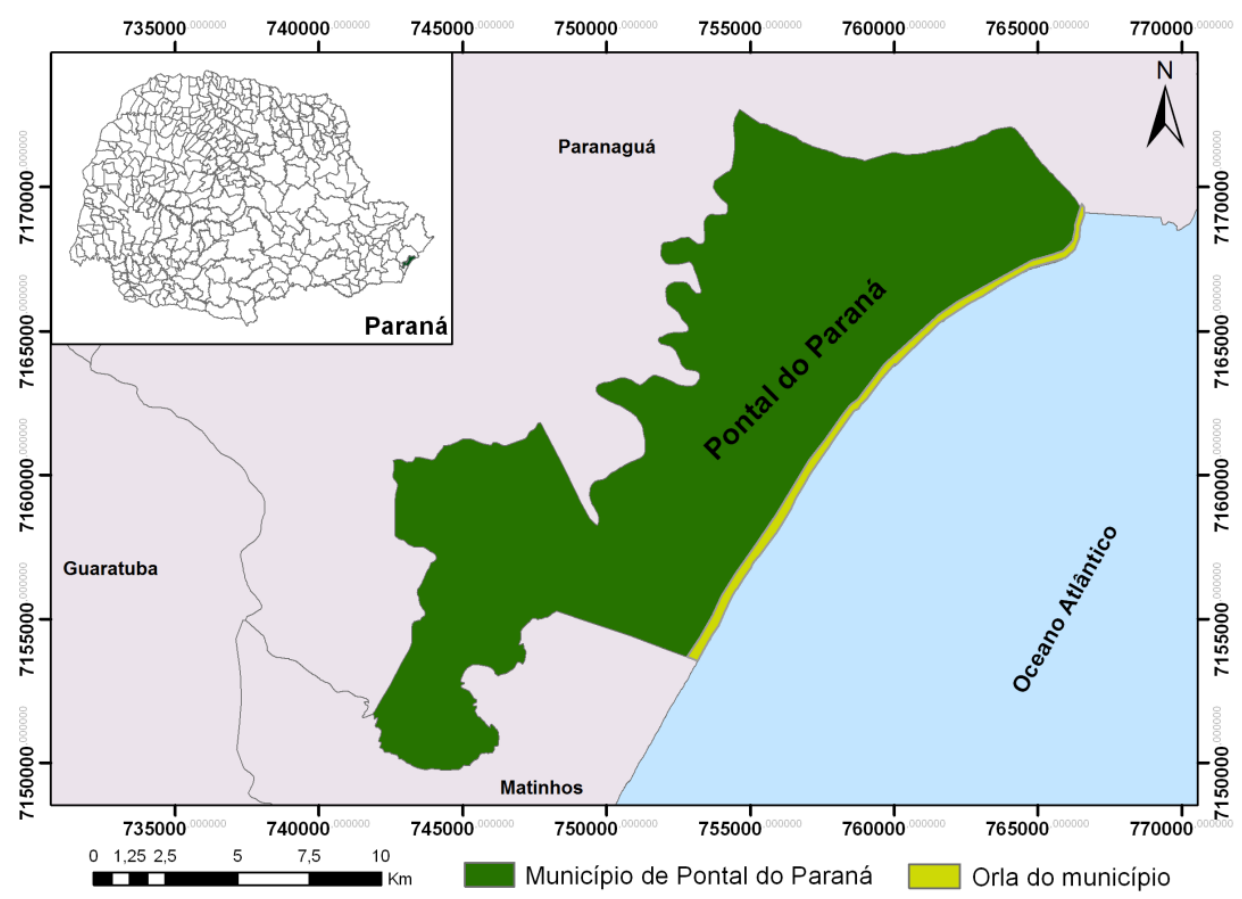

FIGURA 1 - LOCALIZAÇÃO DA ÁREA DE ESTUDO.

FONTE: Os autores (2012)

O munícipio está inserido no Bioma Floresta Atlântica e apresenta fragmentos de matas nativas, como vegetação de restinga em forma de corredor ao longo da faixa de orla, havendo predominância de áreas urbanizadas ao longo da orla com ampla arborização. Compreende ainda, diversos corpos d'água entre naturais e artificiais que deságuam no mar. Apenas os naturais têm suas áreas adjacentes protegidas (COLIT, 2004).

O tipo climático predominante na área é o $\mathrm{Cfa}$, sendo caracterizado como Subtropical Úmido - Mesotérmico com verão fresco, com precipitações abundantes com média pluviométrica em torno de $2.300 \mathrm{~mm}$. A temperatura média do mês mais quente não chega a $22^{\circ} \mathrm{C}$ e é controlado por sistemas tropicais e polares (VANHONI; MENDONÇA, 2008).

Nos meses de alta temporada, o município recebe aproximadamente 400 mil veranistas, distribuídos pelos 48 balneários, que subdividem os 22 quilômetros de praias que compõem a região (COLIT, 2004). Segundo o IBGE (2012), a economia local baseia-se em pequenas indústrias (marcenaria, panificação e serralheria) e, principalmente, no turismo, comércio, pesca e artesanato.

Alguns problemas atuais do município são a presença de ocupações na restinga tal como comércio, imóveis para locação e templo religioso; intervenção dos 
moradores sobre a restinga; degradação da restinga; presença de veículos na praia; falta de destino adequado aos resíduos de pescados; conflitos fundiários e dunas móveis (embrionárias) em Ipanema (MMA, 2003).

A análise da qualidade da paisagem da orla do Município de Pontal do Paraná foi realizada a partir da utilização de dois métodos de estudo da paisagem: direto e indireto. Conforme descreve Pires (1993), o método direto de avaliação da qualidade da paisagem consiste na valoração a partir da contemplação da totalidade da paisagem, pela visualização no local ou pelo uso de substitutos, dando origem a diferentes níveis de subjetividade durante o processo. Já com o método indireto a valoração é realizada pela desagregação da paisagem e da análise de seus componentes ou dos elementos da paisagem, de acordo com diferentes juízos de valor e segundo critérios de pontuação e classificação estabelecidos por especialistas.

Para a análise da qualidade da paisagem pelo método direto, foram estabelecidos pontos de amostragens a cada $5 \mathrm{~km}$ ao longo de toda a extensão da faixa de areia da orla, partindo da porção norte. Desta forma, foram amostrados quatro pontos que se originaram do prolongamento das ruas: Uruguai (P1), Av. Ipanema (P2), Antonina (P3) e Dídio Costa (P4). A partir do prolongamento destas ruas, o ponto de amostragem foi definido como sendo o centro da porção de areia (ponto equidistante entre o fim da vegetação e início do mar).

O agente valorador desta análise foi uma equipe de três pessoas, que efetuaram observação direta (in loco) na área de estudo, em uma época fora de temporada. Em cada unidade amostral foram definidas quatro paisagens amostrais, cada uma correspondente a um giro de $90^{\circ}$ partindo do sentido defronte ao mar,

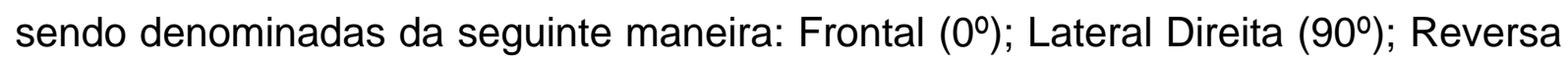
(posição onde o observador fica de costas para o mar, $180^{\circ}$ ) e Lateral Esquerda $\left(270^{\circ}\right)$.

Cada paisagem amostral foi avaliada quanto aos seguintes elementos visuais da composição paisagística: intervisibilidade, diversidade, singularidade, contraste, ação antrópica, característica da vegetação, conservação das características naturais do ambiente, condição de limpeza da areia e presença ou ausência de esgoto. 
Com base nas definições e metodologias propostas por Biondi e Leal (2002) e Gonzaga et al. (2004), para minimizar a interferência da subjetividade dos avaliadores durante a análise, atribuiu-se uma escala de valores aos elementos visuais da composição paisagística:

a) Intervisibilidade - grau de visibilidade ou campo visual da paisagem: (1) restrita - visibilidade até o primeiro plano; (5) média - visibilidade até o segundo plano; (10) ampla - visibilidade acima do segundo plano.

b) Diversidade - existência de variedade paisagística: (1) pequena - há no máximo quatro elementos que se destacam dentro da paisagem; (5) média apresenta de cinco a sete elementos de destaque; (10) grande - apresenta oito ou mais elementos de destaque.

c) Singularidade - grau de atração que o local apresentava, com existência de elementos únicos, de exclusividade: (1) não apresenta variáveis naturais ou antrópicas que se destaquem na paisagem; (3) Apresenta variáveis naturais com força de atração visual dentro da paisagem.

d) Contraste - presença de elementos contrastantes que poderiam aumentar ou diminuir a qualidade visual da paisagem: (1) não apresenta nenhuma característica contraste; (10) Apresenta alguma característica contrastante na linha, cor, forma ou textura da paisagem.

e) Ação antrópica - presença de elemento introduzida pelo homem que exerceriam pressão sobre a paisagem (construções, calçadas, refletores, lixo, barcos, etc.): (1) grande - apresenta cinco ou mais elementos; (5) média - apresenta de três a quatro elementos; (10) pequena - há no máximo dois elementos antrópicos na paisagem.

f) Vegetação - presença ou não deste elemento na paisagem: (1) ausente - a paisagem não é composta por vegetação; (5) baixa - a paisagem é composta por vegetação de porte baixo (herbáceas e arbustos); (10) alta - a paisagem é composta por vegetação de porte alto e/ou arborização introduzida.

g) Conservação das condições naturais do ambiente - análise subjetiva, de acordo com a formação acadêmica de cada um dos avaliadores: (1) mau estado quando observada invasão por espécies não naturais (capim e grama); (10) bom estado - quando observado a vegetação natural (Restinga). 
h) Areia - presença de elementos que caracterizem sujeira: (1) mau estado quando houve visualização de sujeira, galhos e lixo em geral; (10) bom estado quando não houve visualização de sujeira.

i) Esgoto - córregos de água escura que alcançam o mar: (1) apresenta a existência de esgoto a céu aberto; (10) não apresenta a existência de esgoto a céu aberto.

A valoração de cada paisagem amostral foi realizada pela soma do valor atribuído a cada elemento da paisagem avaliado, dividido pelo número total de elementos considerados. Na sequência, foi calculada a média deste valor entre os três avaliadores e por fim a média entre os valores de todas as paisagens amostrais que compõem cada ponto de análise.

As médias obtidas para cada paisagem amostral (Frontal, Lateral Direita, Reversa e Lateral Esquerda) foram submetidas a uma análise de variância. E as médias obtidas para cada ponto de amostragem foram comparadas estatisticamente pelo teste Tukey a 5\% de significância. De acordo com Petersen (1977), este teste é um dos mais apropriados para situações em que os tratamentos são níveis de fator qualitativo e independentes.

Com base na valoração média, cada unidade amostral foi classificada em um dos cinco níveis de qualidade visual: Péssima (0 a 1,99), Ruim (2 a 3,99), Boa (4 a 5,99), Ótima (6 a 7,99) e Excelente (8 a 10).

A análise da qualidade da paisagem, pelo método indireto, consistiu na identificação e valoração dos elementos da paisagem presentes no interior das unidades amostrais. Estas unidades condizem com os mesmos pontos de amostragens utilizados no método direto, com dimensões de $200 \times 200$ metros. As unidades amostrais foram sobrepostas às imagens GeoEye (2012) disponíveis no Google Earth e sua alocação partiu do prolongamento das ruas Uruguai, Av. Ipanema, Antonina e Dídio Costa até o centro da areia, exatamente no ponto onde foi realizado o método direto, a partir daí foram medidos $100 \mathrm{~m}$ para cada lado, delimitando a unidade de 4 ha.

A qualidade da paisagem das unidades amostrais foi analisada considerando sete elementos da paisagem: "Mar", "Areia", "Vegetação alta", "Vegetação baixa", "Acessos", "Esgoto a céu aberto" e "Construções". Cada elemento recebeu um valor de importância, onde a escala empregada para a 
avaliação compreendeu valores inteiros iguais a 1, 5 e 10, sendo 10 , o valor referente à maior importância (Tabela 1).

TABELA 1 - VALORES DE IMPORTÂNCIA ATRIBUÍDOS AOS ELEMENTOS DA PAISAGEM

$\begin{array}{ll}\text { Elementos da paisagem } & \begin{array}{l}\text { Valor } \\ \text { individual }\end{array}\end{array}$

\begin{tabular}{lc}
\hline Mar & 10 \\
Areia & 10 \\
Vegetação alta & 10 \\
Vegetação baixa & 5 \\
Acessos & 5 \\
Esgoto a céu aberto & 1 \\
Construção & 1 \\
\hline
\end{tabular}

FONTE: Os autores $\overline{(2012)}$

Calculou-se então a área que cada elemento ocupou em cada unidade amostral, no programa ArcGis 9.3. A porcentagem que cada elemento representou em toda a unidade amostral foi estimada e a este valor foi multiplicado o seu respectivo valor de importância. Os valores desta porcentagem de representação, ao invés de serem utilizados na escala de 0 a 100, foram utilizados de 0 a 1 , considerando-se duas casas decimais, de modo a obter números de menor grandeza. Com a soma de valores de cada elemento da paisagem, foi obtido um valor de qualidade para o ponto amostrado.

O valor de qualidade da paisagem encontrado pelo método indireto foi multiplicado pelo valor da qualidade da paisagem encontrado pelo método direto, este valor foi então dividido por 10 , obtendo-se um valor final da qualidade da paisagem nas quatro unidades amostrais da orla de Pontal do Paraná.

\section{RESULTADOS E DISCUSSÃO}

A análise da qualidade da paisagem pelo método direto demonstrou variação entre as paisagens amostradas. De maneira geral, as paisagens visualizadas defronte ao mar apresentaram os maiores valores, sendo os menores 
valores encontrados na paisagem amostral "reverso", na qual se observam as construções da beira mar (Tabela 2).

\begin{tabular}{|c|c|c|c|c|c|}
\hline Paisagem amostral & P1 & P2 & P3 & P4 & Média \\
\hline $0^{\circ}$ - Frontal (mar) & 5,9 & 6,7 & 4,8 & 7,9 & 6,3 \\
\hline $90^{\circ}$ - Lateral Direita & 7,3 & 5,2 & 3,1 & 5,7 & 5,3 \\
\hline $\begin{array}{l}180^{\circ}-\text { Reversa } \\
\text { (restinga) }\end{array}$ & 5,2 & 2,4 & 3,1 & 5,9 & 4,2 \\
\hline $270^{\circ}$ - Lateral Esquerda & 7,3 & 5,0 & 4,2 & 5,7 & 5,6 \\
\hline
\end{tabular}

FONTE: Os autores (2012)

Observa-se na tabela 2 que o maior valor encontrado foi na paisagem amostral "Frontal" $(7,9)$ do P4. Nesta, a visualização centralizada do arquipélago dos Currais e a ausência dos elementos: "Antrópico", "Contraste" e "Diversidade", imprimiram beleza cênica em grande magnitude, em relação às demais paisagens. O menor valor, verificado na paisagem "Reversa" $(3,0)$ do P2, ocorreu devido a grande influência antrópica desta paisagem, com a presença de muitas construções e degradação da vegetação nativa. Isto se deve, principalmente, ao fato de os espaços litorâneos terem se transformado nas últimas décadas em áreas de grande interesse social (DANTAS, 2009).

A paisagem resultante da visualização direta do mar em direção ao horizonte pode ser entendida como uma imagem poética, que guarda relações com arquétipos adormecidos no inconsciente das pessoas (SOUSA, 2011). Segundo Brito e Bruhns (2008), o homem se descobre num estado diferente do seu cotidiano, quando está no estado de observador da dimensão e da força do mar. Seja pelos seus mistérios ou pelas narrativas poéticas, o mar exerce um fascínio sobre as pessoas. Sua imensidão e sua força provocam medo e ao mesmo tempo, respeito, excitação e prazer.

Embora as médias obtidas para a paisagem amostral, "Frontal" $(6,3)$, "Lateral Direita" $(5,3)$, "Reversa" $(4,2)$ e "Lateral Esquerda" $(5,6)$ sejam distintas, a análise de variância aplicada não apontou diferença estatística significativa entre elas $(p=0,06)$. Desta forma, estatisticamente, as paisagens amostrais são iguais em 
termos de qualidade da paisagem. Já para as médias de cada unidade amostral, foi constatada diferença estatística (Tabela 3).

TABELA 3 - DISTINÇÃO ENTRE AS MÉDIAS E CLASSIFICAÇÃO DA QUALIDADE VISUAL.

\begin{tabular}{lllll}
\hline $\begin{array}{l}\text { Pontos } \\
\text { amostrais }\end{array}$ & P1 & P2 & P3 & P4 \\
\hline $\begin{array}{l}\text { Médias } \\
\begin{array}{l}\text { Qualidade } \\
\text { visual }\end{array}\end{array}$ & $6,42 \mathbf{a}$ & $4,84 \mathbf{a b}$ & $3,79 \mathbf{b}$ & $6,32 \mathbf{a}$ \\
\hline $\begin{array}{l}\text { Visuidima } \\
\text { ONTE: Os autores (2012) }\end{array}$ & Boa & Ruim & Ótima \\
\hline
\end{tabular}

Com base na tabela 3 é possível observar que P1 e P4 apresentam qualidade visual "Ótima" e se diferenciam estatisticamente de P3, "Ruim". A unidade amostral P2, de qualidade visual "Boa", não se diferencia estatisticamente de nenhum dos três pontos. A espacialização dos pontos de amostragem na Orla Marinha de Pontal do Paraná e as imagens avaliadas podem ser observadas na figura 2.

A unidade amostral P1, apresentou a maior valoração para a qualidade da paisagem. Neste ponto, à esquerda, é visualizado a llha do Mel de maneira expressiva na paisagem, o que caracterizou certa singularidade. Além disso, as demais paisagens amostrais desse ponto são compostas por baixa diversidade de elementos de interferência antrópica e um ótimo estado de limpeza da areia (presente em todas as paisagens). Na paisagem amostral "Reversa", foi encontrado um contraste muito positivo, o tronco de uma árvore na posição horizontal, como forma de escultura, o que remete a um possível tratamento paisagístico para embelezamento do lugar.

Este ponto está inserido em uma área de Condomínio de classe média alta, com acesso restrito por portaria localizada na PR 412 (único acesso de veículos). Caracteriza-se por ser uma praia frequentada quase que exclusivamente por proprietários de residências no Balneário que tornam a localidade elitizada (COLIT, 2004). Segundo a mesma referência, a manutenção e urbanização da orla são realizadas por moradores, o que pode ser inadequado, uma vez que não é compatível com as características de restinga. 


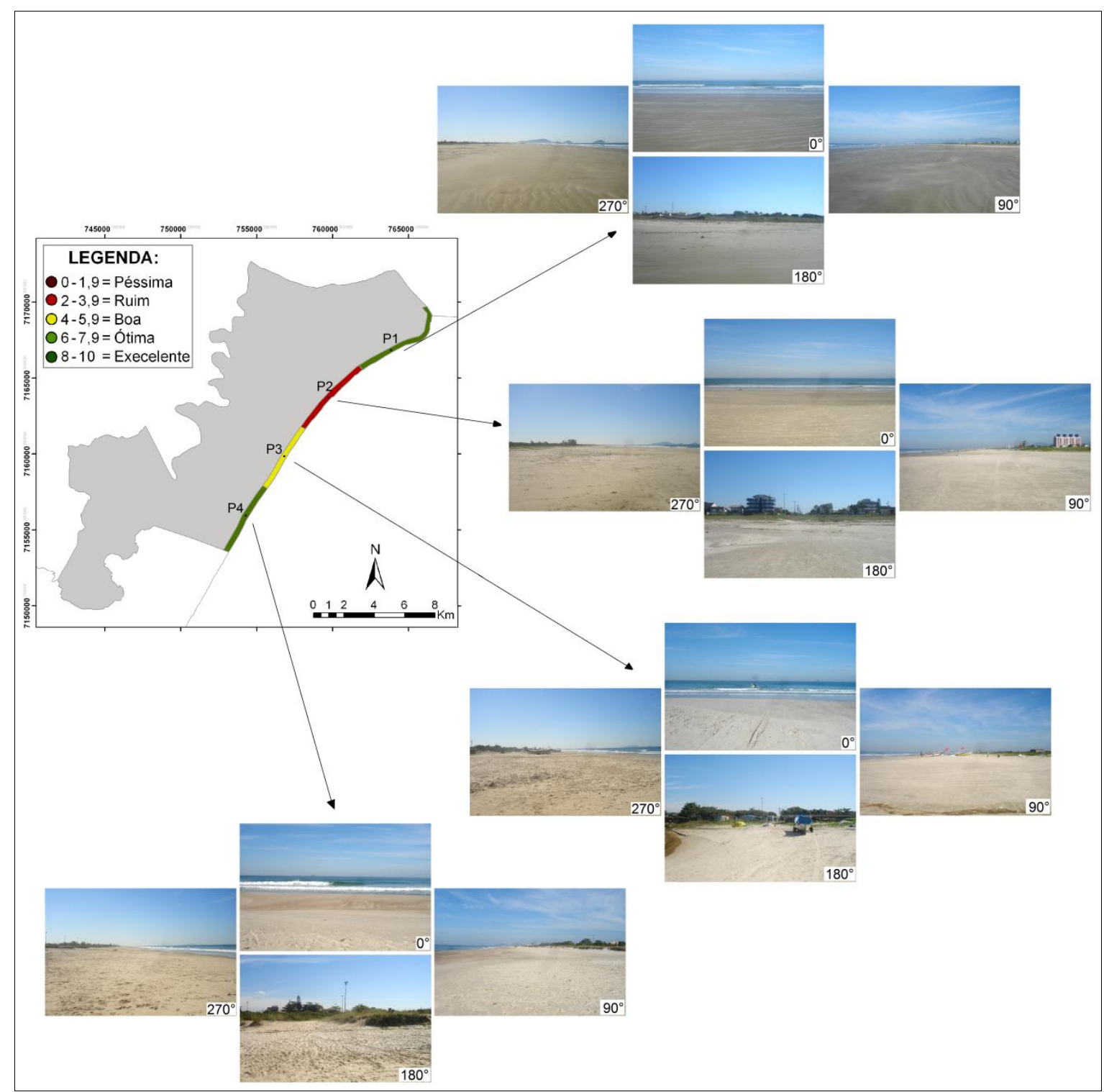

FIGURA 2 - MAPA DA QUALIDADE DA PAISAGEM PELO MÉTODO DIRETO E PAISAGENS AMOSTRAIS EM CADA PONTO.

FONTE: Os autores (2012)

A unidade amostral P4, também recebeu um alto valor para a qualidade da paisagem. Além do Arquipélago de Currais na paisagem "Frontal", a paisagem "Lateral direita" apresenta uma notória participação da Serra do Mar. De maneira geral, o alto valor obtido neste ponto se deve ao excelente estado de limpeza da areia e a existência expressiva de vegetação nativa em bom estado, o que é surpreendente, uma vez que este ponto corresponde à área central do balneário de Praia de Leste, sede administrativa do município e muito frequentada. Neste, há certa interferência antrópica, mas de maneira positiva, como a existência de lixeiras e refletores, o que não é visualizado em nenhum outro ponto. 
A unidade amostral P2, apresentou uma valoração da paisagem média e classificada como "Boa". Este resultado é reflexo do estado de limpeza da areia e da vegetação rasteira introduzida, que atribuem valores negativos a paisagem. Não há grandes atrativos na paisagem, destaca-se apenas como contraste, a existência de um prédio habitacional devido a suas cores, rosa e azul.

A unidade amostral P3, foi o que apresentou a pior qualidade da paisagem: "Ruim". Este resultado é reflexo da existência de uma aldeia de pescadores neste local, o que dificultou inclusive o acesso ao ponto. Assim, nesta unidade amostral há uma grande interferência antrópica negativa, com a existência de estabelecimentos precários, materiais de trabalho sobre a vegetação rasteira introduzida, grande número de barcos e principalmente presença de esgoto a céu aberto. Foi verificado em mais de um ponto amostral, o rastro escuro deixado pelo esgoto quando segue em direção ao mar, variável que evidentemente atribuiu a este ponto o menor valor para a qualidade da paisagem. A paisagem amostral "Reversa" causa a nítida sensação de desordem, devido às habitações e materiais de trabalho dos pescadores localizados sobre o local onde deveria existir vegetação nativa. Faz-se a resalva de que a existência dos barcos coloridos na orla proporcionaram uma paisagem muito agradável e característica do local, entretanto este fator acabou sendo anulado pela presença expressiva do esgoto a céu aberto e da sujeira trazida pelo mar que se deposita na areia.

Segundo o COLIT (2004), neste ponto, o excesso de animais domésticos e a circulação de veículos na orla também faz parte do cenário desta unidade. Além, disso, há também as construções irregulares, com precariedade de infraestrutura, localizadas na faixa costeira entre a linha de costa e a rua à beira mar, utilizadas como moradia e comércio. Estas ocupações irregulares, que ocorrem em fragmentos ao longo da costa, causam degradação ambiental, além da restrição de acesso à praia e perda da beleza cênica.

A análise da qualidade da paisagem realizada pelo método indireto teve início com a classificação da imagem GeoEye, que permitiu delimitar todos os elementos da paisagem que compunha a área de estudo em cada unidade amostral (Figura 3). 


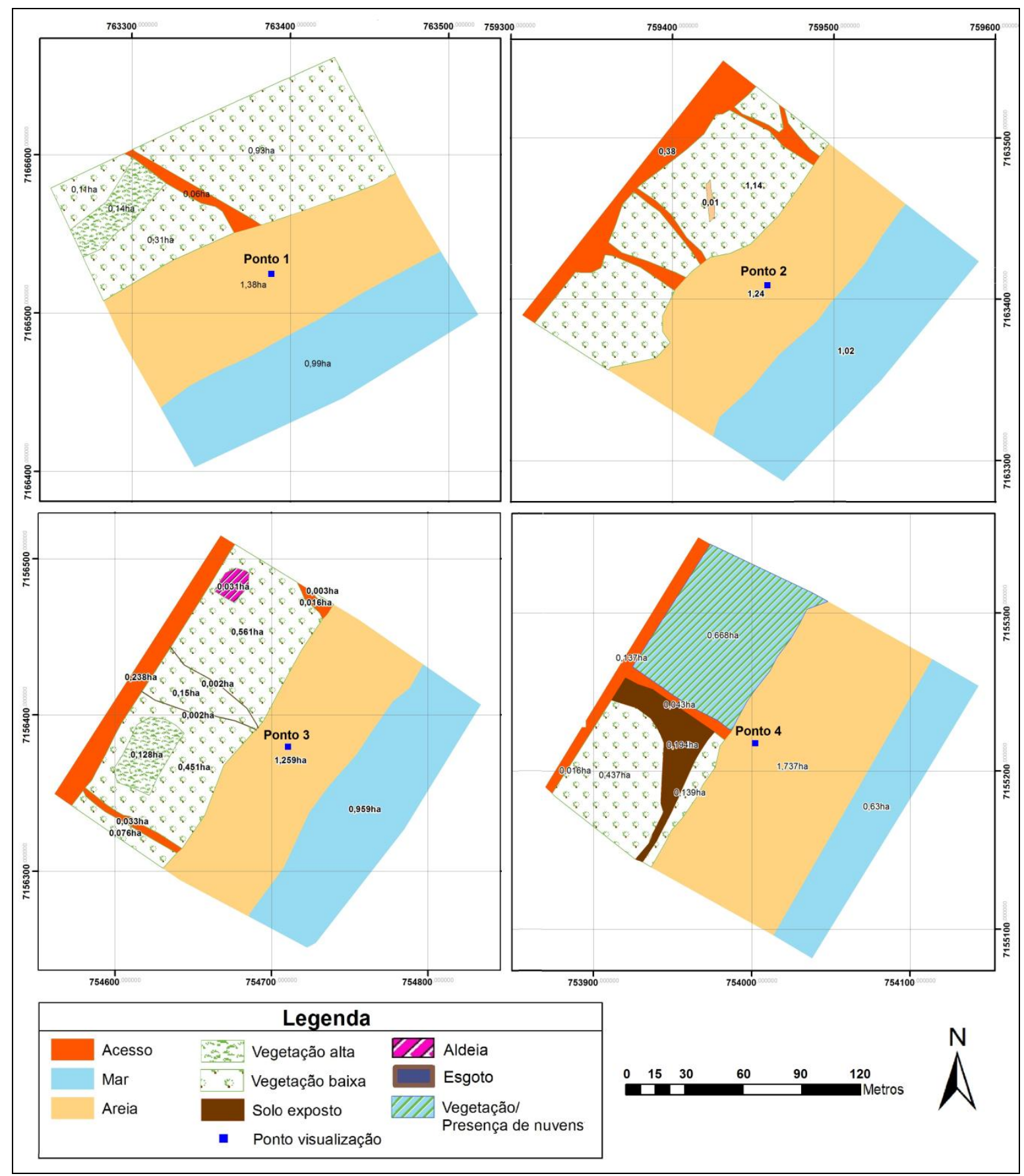

FIGURA 3 - DELIMITAÇÃO DOS ELEMENTOS QUE COMPÕE AS UNIDADES AMOSTRAIS.

NOTA: P1 = unidade amostral 1; P2 = unidade amostral 2; P3 = unidade amostral 3; P4 = unidade amostral 4;

FONTE: Os autores (2012)

Observa-se em P1 uma grande presença de vegetação baixa e poucos acessos, a presença antrópica não é visualizada. Isto provavelmente ocorre porque essa é a parte da praia menos visitada já que seu acesso se dá por dentro de um condomínio. 
Em P2 aparecem indícios de presença humana, devido a grande quantidade de acessos e uma pequena porção de solo exposto, onde deveria ser vegetação, provavelmente causado pela presença do homem.

Em P3 é necessário uma atenção especial justamente pela presença clara e intensiva do homem, inclusive com uma pequena aldeia de pescadores, o que leva a uma maior geração de resíduos que modifica a paisagem com a presença de esgoto que deságua na própria praia.

Em P4 observa-se características de antropização devido a grande área de solo exposto. Porém, é importante ressaltar que não foi possível identificar pela imagem o tipo de vegetação neste ponto pela presença de nuvens na imagem, considerou-se vegetação baixa pelas informações que se tinha no método direto realizado nesse estudo.

Para auxiliar no entendimento da comparação quantitativa dos elementos da paisagem de cada unidade amostral, foram organizados na tabela 4 a quantificação em hectares (ha) de cada elemento que compôs as unidades amostrais P1, P2, P3 e P4.

TABELA 4 - QUANTIFICAÇÃO DOS ELEMENTOS DA PAISAGEM EM CADA UNIDADE AMOSTRAL.

\begin{tabular}{lcccccccc}
\hline \multirow{2}{*}{$\begin{array}{l}\text { Elementos da } \\
\text { Paisagem }\end{array}$} & \multicolumn{3}{c}{ P1 } & \multicolumn{2}{c}{ P2 } & \multicolumn{2}{c}{ P3 } & \multicolumn{2}{c}{ P4 } \\
\cline { 2 - 9 } & $\begin{array}{c}\text { Área } \\
\text { (ha) }\end{array}$ & (\%) & $\begin{array}{c}\text { Área } \\
\text { (ha) }\end{array}$ & (\%) & $\begin{array}{c}\text { Área } \\
\text { (ha) }\end{array}$ & (\%) & $\begin{array}{c}\text { Área } \\
\text { (ha) }\end{array}$ & (\%) \\
\hline Mar & 0,99 & 25,0 & 1,02 & 26,9 & 0,96 & 24,5 & 0,6 & 15,7 \\
Areia & 1,38 & 34,9 & 1,24 & 32,7 & 1,26 & 32,2 & 1,7 & 43,4 \\
Vegetação alta & 0,14 & 3,50 & 0 & 0 & 0,13 & 3,3 & 0 & 0 \\
Vegetação baixa & 1,38 & 34,9 & 1,14 & 30,1 & 1,24 & 31,7 & 1,2 & 31,1 \\
Acessos & 0,06 & 1,50 & 0,38 & 10,0 & 0,29 & 7,3 & 0,2 & 4,9 \\
Esgoto a céu & 0 & 0 & 0 & 0 & 0 & 0,1 & 0 & 0 \\
aberto & 0 & 0 & 0,01 & 0,3 & 0,03 & 0,8 & 0,2 & 4,8 \\
Construções/Solo & 0 & & & & & & &
\end{tabular}

Verificou-se que o elemento "Mar" ocupou maior área na unidade amostral em P2 do que nas demais unidades, a unidade que apresentou menor área de mar foi em P4. A faixa de areia mais larga estava presente em P4, enquanto a mais 
estreita encontrava-se em P2. O elemento "Vegetação Alta" foi encontrado somente em P1 e P3. Em P4, não foi possível identificar uma parte da unidade amostral, devido à presença de nuvens na imagem analisada, assim, para esta situação, utilizou-se do conhecimento prévio da área, que permitiu classificá-la como "Vegetação Baixa". Este elemento apresentou um percentual maior em P1, seguido de P3, P4 e P2. Tal fato é decorrente do processo de regeneração natural pelo qual a área está passando após terem cessado com as atividades que degradavam o ambiente.

O elemento "Acesso" ocupou área substancial em todas as unidades com exceção da unidade $\mathrm{P} 1$, onde a cobertura foi insignificante. O elemento "Esgoto a céu aberto" ocorreu somente em P3 e representou uma pequena área, isto se justifica porque o esgoto aparece como uma fina linha na imagem. O elemento "Construção" apareceu somente em P3 e de forma insignificante, neste foi possível quantificar apenas um glomerado urbano (denominado de aldeia), não se trata exatamente de uma vila de pescadores e sim de construções irregulares e sem a menor infraestrutura. O elemento "Solo exposto" esteve presente somente em P4 e foi em decorrência da pavimentação do acesso, pelo fato desta unidade estar em ponto centralizado da orla.

As quatro unidades amostrais analisadas encontram-se inseridas em uma área com características semelhantes, formada por uma extensa e contínua praia, de areias finas a médias, geralmente de baixa declividade (COLIT, 2004), Segundo a mesma referência, é bastante comum a presença de dunas embrionárias frontais, ecologicamente importantes (rota de bandos de aves migratórias), não havendo indícios de processos erosivos marinhos. A urbanização desta unidade manteve uma pequena faixa frontal de vegetação nativa (restinga). Os principais valores cênicos desta unidade são a própria praia, pois possui balneabilidade adequada em quase toda a sua extensão, e a vista do arquipélago dos Currais.

Desta forma é possível observar que a qualidade da paisagem, analisada pelo método indireto apresentou resultado distinto aos encontrados pelo método direto (Tabela 5). Quando se comparam os dois métodos, é possível afirmar que o método indireto pouco distinguiu os pontos amostrais ao longo da orla, embora tenha existido distinção de classes, a diferença entre a melhor e a pior unidade, numericamente, foi de apenas 0,42. 
TABELA 5 - VALORAÇÃO DOS ELEMENTOS DA PAISAGEM E CLASSIFICAÇÃO DA QUALIDADE DA PAISAGEM PELO MÉTODO INDIRETO.

\begin{tabular}{lllll}
\hline $\begin{array}{l}\text { Elementos da } \\
\text { Paisagem }\end{array}$ & $\mathbf{P 1}$ & $\mathbf{P 2}$ & $\mathbf{P 3}$ & $\mathbf{P 4}$ \\
\hline Mar & 250,6 & 269,1 & 245,3 & 157,5 \\
Areia & 349,4 & 327,2 & 322,1 & 434,1 \\
Vegetação alta & 35,4 & 0 & 32,7 & 0 \\
Vegetação baixa & 174,7 & 150,4 & 158,7 & 155,5 \\
Acessos & 7,6 & 50,1 & 36,7 & 24,5 \\
Esgoto a céu aberto & 0 & 0 & 0,1 & 0 \\
Construção/Solo & 0 & 0,3 & 0,8 & 4,8 \\
exposto & 817,7 & 797,1 & 796,4 & 776,4 \\
\hline Total & 8,18 & 7,97 & 7,96 & 7,76 \\
\hline Total/100 & Excelente & Ótima & Ótima & Ótima \\
\hline Qualidade & \multicolumn{3}{r}{}
\end{tabular}

FONTE: Os autores (2012)

Com base na tabela 5, nota-se que foram encontradas duas classes de qualidade da paisagem: "Excelente" em P1 e "Ótima" nas demais unidades amostrais. Observa-se ainda, que a pequena variação entre as unidades amostrais ocorreu devido à homogeneidade na proporção dos elementos que compõe a paisagem, possíveis de serem identificados em vista aérea. Nota-se que os valores dos elementos "Mar" e "Areia" foram os maiores, em todas as unidades. Isto ocorreu porque estes dois elementos juntos, em todos os pontos, cobriram mais da metade da área amostrada, além de apresentarem um valor de importância alto (10).

O elemento "Vegetação baixa" também apresentou valores semelhantes em todos os pontos, pois este cobria a maior parte de todas as unidades amostrais. $\mathrm{O}$ elemento "Vegetação alta", caracterizado por uma restinga em melhor estado de conservação, foi encontrada apenas nos pontos P1 e P3. Desta forma, esperava-se que nestas unidades a qualidade da paisagem fosse maior, no entanto, a menor proporção do elemento "Acesso" em P1 e a existência do elemento "Esgoto a céu aberto" em P3, contribuíram para diminuir a valoração. De maneira geral, a análise da paisagem pelo método indireto não permitiu diferenciar os pontos amostrados entre si, demonstrando uma homogeneidade da paisagem da orla marinha.

A análise da qualidade da paisagem realizada com a união dos métodos direto e indireto demonstrou como resultado final a variação entre as unidades amostradas. $O$ fator que torna essa união dos métodos mais eficiente do que a 
análise isolada de ambos, é a possibilidade de confrontar informações e obter uma análise melhor da paisagem, pois o que não se vê na imagem é perfeitamente visível in loco (Tabela 6).

Tabela 6. Valoração final da qualidade da paisagem da orla marinha do município de Pontal do Paraná, PR.

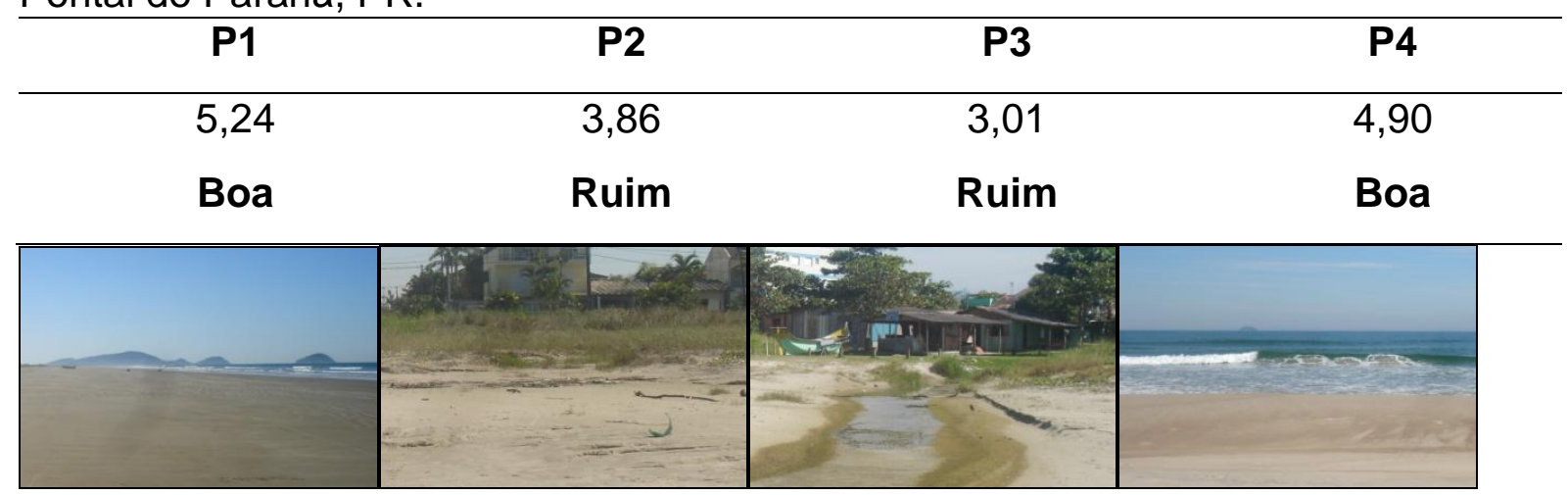

FONTE: Os autores (2012)

Observa-se na tabela 6 que a qualidade da paisagem nos pontos $\mathrm{P} 2$ e $\mathrm{P} 3$ foi classificada como "Ruim" e em P1 e P4 apresentaram qualidade da paisagem "Boa". Esta diferenciação entre as amostras teve como principal responsável o método direto, uma vez que no método indireto, ocorreu uma homogeneização da área. Assim, como já mencionado anteriormente, $\mathrm{P} 1$ e P4 apresentaram atrativos naturais significativos observados no método direto, a llha do Mel (P1) ० Arquipélago de Currais (P4), além do significativo estado de limpeza da areia nesses dois locais.

Os atrativos naturais citados destacam-se na paisagem, pois sobressaem à linha do horizonte, quebrando a monotonia do relevo plano. Em pesquisas que analisam a percepção de paisagem, é conhecido mundialmente o gosto das pessoas por paisagens que apresentem relevo acidentado (GOMIDE et al.,2010). Segundo Tuan (2012), o relevo acentuado, como as montanhas e locais altos, exerce uma grande atração ao ser humano.

A unidade amostral P2 foi classificada como "Ruim", devido ao estado de limpeza da areia e da vegetação rasteira introduzida. Infere-se que este resultado foi devido à influência antrópica negativa exercida sob esse local, aliado a ausência de atrativos da paisagem. A unidade amostral P3 também foi classificada como "Ruim", no entanto, o valor obtido foi o pior entre as quatro unidades. Este resultado deve-se 
à interferência antrópica acentuada nesta área, principalmente representada pelas habitações irregulares inseridas na orla.

As unidades analisadas, segundo o Plano de Intervenção na orla marítima de Pontal do Paraná, elaborado pelo COLIT (2004) apresentam usos compatíveis com a manutenção da qualidade ambiental e baixo potencial de impacto. Este plano propõe também uma revitalização urbanística, respeitando às exigências legais da área de Preservação Permanente, sendo permitida a ocupação controlada, ordenada e restrita às comunidades tradicionais antigas, seguindo as orientações legais para as áreas de uso comum, mas não é o que de fato ocorre ao longo da orla.

Devido à tendência ao adensamento da população e da ocupação desordenada nas áreas de uso comum, ocorre a perda da vegetação nativa (biodiversidade). Inácio (2004) observou que a restinga do munícipio de Pontal do Paraná vem sendo impactada pela circulação de pessoas, veículos, despejo de detritos sólidos, terraplanagens, construção de campos, gramados e calçadões que alteram a vegetação e o regime hidrográfico natural e, consequentemente, a deposição de sedimentos marinhos. Destaca-se também que a proximidade do porto de Paranaguá contribui para que a paisagem da orla de Pontal do Paraná seja afetada pela presença de filas de navios e também pelos possíveis impactos oriundos das atividades deste porto, fato que também afeta a qualidade da paisagem.

Em estudo de valoração da paisagem, também no litoral paranaense, no município de Matinhos, Leal e Biondi (2003) encontraram resultados semelhantes, tal como baixos valores nos espaços de ocupações irregulares, com inexistência de infraestrutura urbana e degradação do meio ambiente e valores altos nos ambientes com maior grau de naturalidade do meio, diversidade ecológica e presença de infraestrutura urbana.

\section{CONCLUSÕES}

A análise da qualidade da paisagem da orla do Município de Pontal do Paraná com da união dos métodos direto e indireto resultou em baixos valores de 
qualidade. Dois pontos analisados foram classificados como "Ruim" e outros dois pontos como "Bom".

As paisagens visualizadas defronte ao mar apresentaram maior qualidade e as visualizadas de costas ao mar a menor. Os atrativos naturais tais como, a llha do Mel e o Arquipélago de Currais foram os elementos responsáveis pela elevação da qualidade da paisagem nos ambientes estudados, além do grau de limpeza da praia. Em contrário, a percepção da interferência antrópica negativa e a supressão da vegetação foram os elementos responsáveis pela diminuição da qualidade.

Recomenda-se em trabalhos futuros desta natureza, realizar a amostragem durante o verão, época de temporada nas praias, pois a tendência é que haja uma modificação da paisagem com o aumento da população.

\section{Referências}

BIONDI, D.; LEAL, C. T. Análise da Capacidade Paisagística do Parque Estadual de Vila Velha - PR. In: CONGRESSO BRASILEIRO DE UNIDADES DE CONSERVAÇÃO, 3, 2002, Fortaleza, CE. Anais do... Fortaleza: Rede Nacional PróUnidades de Conservação, 2002, p. 359-367.

BRASIL. Ministério do Meio Ambiente - MMA. Panorama dos Ecossistemas Costeiros e Marinhos no Brasil / Secretaria de Biodiversidade e Florestas/Gerência de Biodiversidade Aquática e Recursos Pesqueiros. - Brasília: MMA/SBF/GBA, $2010 . \quad 148 \quad$ p. Disponível: <http://www.mma.gov.br/estruturas/205/_publicacao/205_publicacao2707201104223 3.pdf> . Acessado e m 29/09/2012.

BRASIL. Ministério do Meio Ambiente - MMA. Plano de Gerenciamento Costeiro. Disponível: <http://www.mma.gov.br/estruturas/sqa_sigercom/_arquivos/pngc2.pdf>. Acessado em 28/09/2012.

BRITO, Telma Medeiros; BRUHNS, Heloisa Turini. Corpo, lazer e natureza: uma reflexão sobre os cruzeiros marítimos. Turismo em Análise, São Paulo, v. 19, n. 1, p. 125-136, 2008.

CONSELHO DE DESENVOLVIMENTO TERRITORIAL DO LITORAL PARANAENSE (COLIT). Plano de intervenção na orla marítima de Pontal do Paraná. Paraná, 2004, 64 p.

FALCÃO, S. M.; LIMA, E. R. V.; BORGES, U. N. Alterações na paisagem da orla marítima de Cabedelo em decorrência da dinâmica de ocupação da Área. Cadernos do Logepa - João Pessoa, PB, DGEOC/CCEN/UFPB. Vol. 4, n. 1, p.1-14, 2005. 
GEOBRASII. 2002. O estado do meio ambiente no Brasil. Disponível: $<$ http://www.uff.br/cienciaambiental/biblioteca/geobrasil/amb_marinhos.pdf $>$. Acesso em 22/06/2012.

GOMIDE, L. R.; COSTA, E.R.O.; CORRAZZA, A. P; BIONDI, D. Avaliação paisagística de um trecho da rodovia PR-340, Antonina, Paraná, Brasil. Floresta, Curitiba, PR, v. 40, n. 4, p. 701-710, out./dez. 2010.

GONZAGA, C. A. M.; WANDEMBRUCK, A.; SEGER, C. D.; BIONDI, D. Análise paisagística da trilha recreativa do Parque Municipal do Passaúna, Curitiba, Paraná. Caderno da Biodiversidade, v. 4, n. 2, dez, 2004, p. 66-73.

IGNÁCIO, G. M.; REBULI; K. B.; KRUG, L. A.; KOTLER, L.; TEL; M. P.; PATCHINEELAM, S. M.. Consequências da intervenção antrópica na zona costeira: um exemplo do litoral do Paraná. Disponível: <http://www.uesb.br/anpuhba/artigos/anpuh_II/gabriela_m_ignacio.pdf>. Acesso em 28/07/2012.

INSTITUTO BRASILEIRO DE GEOGRAFIA E ESTATÍSTICA (IBGE). Cidades, Pontal do Paraná. Disponível: <http://www.ibge.gov.br/cidadesat>. Acesso em 10/07/ 2012.

LAURIE, M. 1975. An introduction to landscape architecture. America Elsevier Pub, New York, $304 \mathrm{p}$.

LEAL, C. T.; BIONDI, D. A valoração paisagística aplicada ao planejamento ambiental urbano: estudo de caso do município de Matinhos - PR. Anais... XI SBSR, Belo Horizonte, Brasil, 05 - 10 abril 2003, INPE, p.1847 - 1854.

MANOSSO, F.C. 2005. O estudo da paisagem no município de Apucarana, PR: As relações da estrutura geoecológica e a organização do espaço. Dissertação. PPG em Geografia, UEM, Maringá, PR. 117p.

NUCCI, J. C. Aspectos teóricos do Planejamento da Paisagem. In: Planejamento da Paisagem como subsídio para a participação popular no desenvolvimento urbano. Estudo aplicado ao bairro de Santa Felicidade Curitiba/PR. Org. João Carlos de Nucci. Curitiba: LABS/DGEOG/UFPR. 2010, 277p.

PETERSEN, G. R. Use and misuse of multiple comparison procedures. Agronomy Journal, 69 (2): 1977, p.205-208.

PIRES, P. S. Avaliação da qualidade visual da paisagem na região carbonífera de Criciúma - SC. Curitiba, 1993. 71 f. Dissertação (Mestrado em Engenharia Florestal) - Setor de Ciências Agrárias, Universidade Federal do Paraná.

REDE CEDES. 2012. Pontal do Paraná. Curitiba. Disponível: <http://www.redecedes.ufpr.br/Pontal\%20do\%20Paran\%E1.html>. Acesso em: 02/06/2012. 
SIMIÃO, M. S.; FISCHER, M. L.. Estimativa e inferências do método de controle do molusco exótico Achatina fulica BOWDICH 1822 (STILOMMATOPHORA; ACHATINIDAE) em Pontal do Paraná, Litoral do Estado do Paraná. Caderno da Biodiversidade, v. 4, n. 2, dez. 2004.

SOUSA, A. N de. Paisagens litorâneas urbanas: novas perspectivas de análise. Fortaleza: Mercator - Revista de Geografia da UFC, v. 10, n. 21, jan.-abr, 2011, p. 91-102.

TUAN, Y. F. Topofilia: um estudo da percepção, atitudes e valores do meio ambiente. Tradução de Lívia de Oliveira. Londrina: Eduel, 2012. 342 p.

VANHONI, F; MENDONÇA, F. 2008. O Clima Do litoral do Estado do Paraná. Revista Brasileira de Climatologia. ISSN: 1980-055X. Disponível: <http://ojs.c3sl.ufpr.br/ojs2/index.php/revistaabclima/article/view/25423/17042>. Acesso em 02/06/2012.

XAVIER-DA-SILVA, J. (Org.); ZAIDAN, R. T. (Org.). Geoprocessamento \& Meio Ambiente. $1^{\underline{a}}$ Ed. Rio de Janeiro: Bertrand Brasil, 2011. V. 1. 328p.

(Recebido em 22.04.2013; Aceito em: 09.09.2013) 